Revista Destaques Acadêmicos, Lajeado, v. 10, n. 4, 2018. ISSN 2176-3070

DOI: http://dx.doi.org/10.22410/issn.2176-3070.v10i4a2018.2047

http://www.univates.br/revistas

\title{
DETECÇÃO DE ADULTERAÇÃO E CARACTERIZAÇÃO FÍSICO-QUÍMICA DE MEL DE ABELHA DE PEQUENOS PRODUTORES DO INTERIOR GAÚCHO
}

\author{
Renata Pelin Viciniescki ${ }^{1}$, Sabrina Grando Cordeiro², \\ Eniz Conceição Oliveira ${ }^{3}$
}

Resumo: Este trabalho objetivou analisar qualitativamente e por parâmetros estabelecidos em normativas, méis comercializados em pequenas propriedades do Sul do Brasil visando a detecção de fraude. As cinco amostras de mel foram submetidas a análises de Reação de Fiehe, Lugol e Lund, além de adição de corantes, acidez total e pH, nas quais todas as amostras não apresentaram indícios de fraude e o pH estabeleceu-se na faixa de 3 . Assim constata-se que análises para fraude de méis podem ser realizadas através de testes analíticos qualitativos clássicos.

Palavras-chave: mel, adulteração, Rio Grande do Sul.

\section{INTRODUÇÃO}

O mel é um dos alimentos mais antigos que se tem conhecimento, onde quase todas as civilizações antigas utilizavam-no para algum fim, seja como alimento ou para uso medicinal (ANDRADE et al., 2012). O mel é o principal produto de abelhas melíferas, e apesar de ser uma mistura de açúcares como a frutose e glicose, possui vários outros compostos, assim como carboidratos, compostos fenólicos e flavonoides, além de minerais, aminoácidos, enzimas, proteínas e diversas vitaminas (AZEVEDO-BENITEZ, NOGUEIRA-COUTO, 1988).

1 Graduanda em Engenharia Química pela Universidade do Vale do Taquari - Univates. Lajeado, RS, Brasil. E-mail: renata.viciniescki@universo.univates.br

2 Graduanda em Engenharia Química pela Universidade do Vale do Taquari - Univates. Lajeado, RS, Brasil. E-mail: sabrina.cordeiro@universo.univates.br

3 Doutorado na Universidade Federal do Rio Grande do Sul - Professora titular na Universidade do Vale do Taquari - Univates. Lajeado, RS, Brasil. E-mail: eniz@univates.br 
Deste modo o mel é um alimento utilizado mundialmente e assim a demanda, aumenta mais a cada ano. Na tentativa de suprir esse mercado, a produção mundial anual, aproxima-se a 1.636 .399 toneladas, onde o país líder na produção de mel é a China, produzindo cerca de 446.089 toneladas por ano, seguida pela Turquia, com produção de 94.245 toneladas ao ano (FAO, 2011), enquanto que no Brasil a produção de mel estima-se em 41.594 ton/ano (IBGE, 2017).

O consumo interno de mel no Brasil apresentou queda nos últimos anos, de $110 \mathrm{~kg} / \mathrm{hab} /$ ano em 2007 para $49 \mathrm{~kg} / \mathrm{hab} /$ ano em 2014, porém o mercado internacional está chamando atenção de apicultores brasileiros pois o valor do mel no exterior cresceu mais de $246 \%$ nos últimos 10 anos, despertando um interesse maior em produzir quantidades superiores de mel (ABEMEL/MAPA, 2015).

Esse desejo de expandir cada vez a produção, estimula alguns produtores a adulterarem seu produto a fim de obter um maior rendimento. As adulterações mais comuns são a adição de açúcares comerciais, como glicose comercial, solução ou xarope de sacarose, melaço e solução de sacarose invertida (ROSSI et al., 1999).

Conduziu-se este trabalho, com o objetivo de analisar os méis comercializados por pequenos produtores da região nordeste do interior do Rio Grande do Sul, com objetivo de indicar a presença de albuminoides, amido e dextrinas, adição de corantes, para tanto realizou-se e avaliação da acidez livre, lactônica e total, e pH, a fim de detectar fraude no mel.

\section{MATERIAL E MÉTODOS}

A pesquisa foi realizada no campus da Universidade do Vale do Taquari - Univates, nos meses de agosto a novembro/2018. As amostras de mel foram coletadas de pequenos produtores do interior do estado do Rio Grande do Sul, no mês de agosto de 2018, onde para as análises e avaliações, utilizou-se a metodologia oficial do Ministério da Agricultura de 1981 e do Instituto Adolfo Lutz de 1985 (BRASIL, 1981; INSTITUTO ADOLFO LUTZ, 1985).

\subsection{Coleta das amostras}

Foram utilizadas cinco amostras de mel, sendo que todas as análises foram feitas em triplicata, coletadas nas propriedades dos produtores, tendo aproximadamente $500 \mathrm{~g}$ de produto e reservadas em frascos de polietileno, Das amostras coletadas, duas amostras originam-se da cidade de Serafina Corrêa, duas amostras da cidade de Gravataí e a quinta amostra da cidade de Muçum.

As amostras de Serafina Corrêa foram nomeadas como "A" e "B", as amostras de Gravataí, nomeadas como " $\mathrm{C}$ " e " $\mathrm{D}$ " e a amostra de Muçum chamada por "E". 


\subsection{Testes químicos qualitativos}

Todas análises qualitativas foram realizadas pelo método clássico de análise em triplicata.

\subsubsection{Reação de Fiehe}

A reação de Fiehe com resorcina em meio ácido serve para indicar a presença de substâncias produzidas durante o superaquecimento de mel (onde o produto perde algumas propriedades) ou a adição de xaropes de açúcares.

Para essa análise pesou-se $5 \mathrm{~g}$ de amostra em um béquer de $50 \mathrm{~mL}$, após foram adicionados $5 \mathrm{~mL}$ de éter seguida de agitação vigorosa. A camada etérea foi transferida para um tubo de ensaio e adicionou-se $0,5 \mathrm{~mL}$ de solução clorídrica de resorcina. A solução foi deixada em repouso por 10 minutos. Nesta análise quando na presença de glicose comercial ou de mel superaquecido, aparecerá uma coloração vermelha intensa, indicando a fraude (BRASIL, 1981).

\subsubsection{Reação de Lugol}

A reação de Lugol mostra se houve adição de amido e/ou dextrinas ao mel. A análise iniciou-se com a pesagem de $10 \mathrm{~g}$ da amostra em um béquer de $50 \mathrm{~mL}$. Adicionou-se $20 \mathrm{~mL}$ de água e agitou-se. As triplicatas foram deixadas no banho-maria à $100^{\circ} \mathrm{C}$ por 1 hora e em seguida refrigerou-se à temperatura ambiente. Após foi adicionado $0,5 \mathrm{~mL}$ da solução de Lugol. Na presença de glicose comercial ou xaropes de açúcar, a solução fica colorida de marromavermelhada a azul (INSTITUTO ADOLFO LUTZ, 1985).

\subsubsection{Reação de Lund}

A reação de Lund é aplicável em amostra de mel e indica a presença de albuminoides, proteína natural presente apenas em méis de abelha, onde meis artificiais não os possuem, assim a ausência de albuminoides indica fraude.

Pesou-se, cerca de $2 \mathrm{~g}$ de mel de cada amostra de mel, em triplicata. Transferiu-se para uma proveta de $50 \mathrm{~mL}$, com tampa, com o auxílio de $20 \mathrm{~mL}$ de água. Adicionou-se $5 \mathrm{~mL}$ de solução de ácido tânico $0,5 \%$ e avolumou-se com água até completar $40 \mathrm{~mL}$. Agitou-se. As amostras foram deixadas em repouso por 24 horas. Assim na presença de mel puro, forma-se um precipitado no fundo maior que $0,6 \mathrm{~mL}$ (BRASIL, 1981).

\subsubsection{Corantes}

Esse teste indica se foram adicionados corantes ao mel. Iniciou-se com a pesagem de cerca de $1 \mathrm{~g}$ de mel e dissolveu-se em $10 \mathrm{~mL}$ de água destilada. Em seguida foi adicionado cerca de $2 \mathrm{~mL}$ de solução de ácido sulfúrico a $5 \%(\mathrm{v} / \mathrm{v})$ previamente preparado. O mel deve permanecer com a coloração inalterada. Se 
existem substâncias corantes adicionadas ao mel, a cor passa gradualmente de violeta a rosa (INSTITUTO ADOLFO LUTZ, 1985).

\subsection{Testes físico-químicos}

Para as avaliações físico-químicas, os testes foram realizados em duplicata para a Acidez Total e $\mathrm{pH}$.

\subsubsection{Acidez Total}

A Acidez total no mel é determinada através da soma da Acidez Livre e da Acidez Lactônica. A Acidez Livre pode ser obtida por meio da titulação com hidróxido de sódio $(\mathrm{NaOH} 0,05 \mathrm{M})$ até que a solução atinja o pH de 8,5.

Aplicando-se a Equação 1:

$$
\text { Acidez livre }(\mathrm{mEq} / \mathrm{kg})=\frac{(V a-V b) \times 50 \times f}{P}
$$

(Equação 1)

onde $V a$ é o volume de $\mathrm{NaOH}$ gasto na titulação da amostra, o $V b$ é o volume gasto na titulação do branco, of é o fator de correção da solução, e o $P$ é a massa da amostra.

Já para a Acidez Lactônica, é necessário, imediatamente após a solução atingir o pH 8,5, acrescer $10 \mathrm{~mL}$ de hidróxido de sódio $(\mathrm{NaOH})$ 0,05 M, continuando-se a titulação com o ácido clorídrico $0,05 \mathrm{M}$ até que a solução atinja pH 8,3. A partir da Equação 2 determinou-se a Acidez Lactônica:

$$
\text { Acidez Lactônica }(\mathrm{mEq} / \mathrm{kg})=\frac{(10-V c) \times 50 \times f}{P}
$$

(Equação 2)

onde $V c$ é o volume de $\mathrm{HCl}$ gasto na titulação, $f^{\prime}$ é o fator de correção da solução de ácido clorídrico e $P$ é a massa da amostra (INSTITUTO ADOLFO LUTZ, 1985).

\subsection{2 $\mathrm{pH}$}

Utiliza-se um pHmetro de sólidos para a análise de $\mathrm{pH}$ das amostras de méis, preparadas em béquer de $50 \mathrm{~mL}$.

\section{RESULTADOS E DISCUSSÕES}

Nos testes realizados que necessitavam de massa de amostra pesada, os valores obtidos estão expostos nos resultados relativos a cada análise e seu desvio padrão respectivo está ao lado entre parênteses. 
Para a primeira análise realizada, a Reação de Fiehe pesou-se aproximadamente de $5 \mathrm{~g}( \pm 0,62 \mathrm{~g})$ de cada amostra de mel, que após a reação apresentaram coloração marrom clara, indicando que não ocorreu superaquecimento do mel ou a adição de xaropes de açúcares, essa coloração obtida pode ser observada na Figura 1.

Figura 1 - Tubos de ensaio com os méis submetidos à análise de Reação de Fiehe

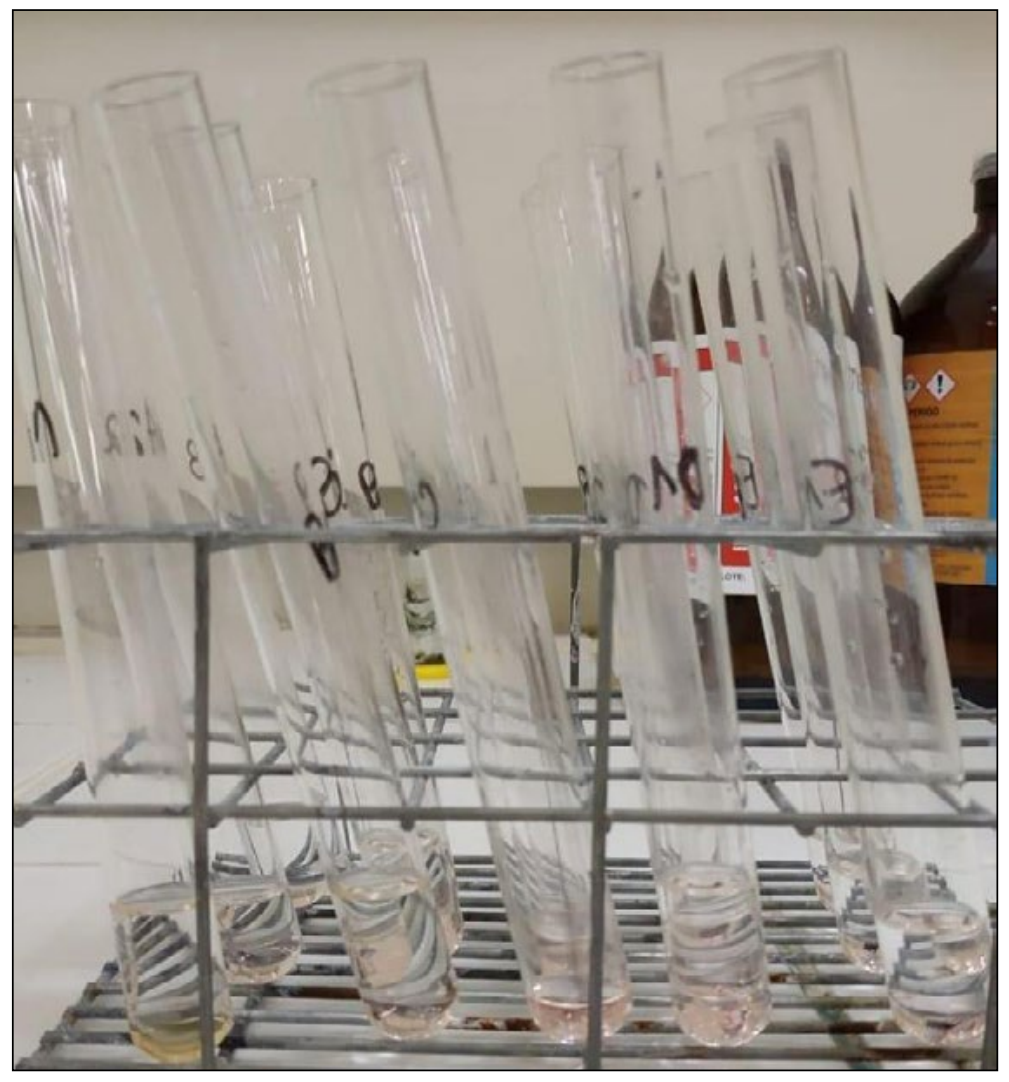

Fonte: Dos Autores (2018).

Já Finco, Moura e Silva (2010), obtiveram cerca de 25\% das amostras em desacordo com a legislação. A reação de Fiehe é uma medida que pode indicar armazenamento inadequado do produto, assim como superaquecimento e possível adulteração com açúcar invertido. Essas características implicam em uma redução significativa nas propriedades nutritivas do mel, pois promove a destruição de diversas vitaminas e enzimas presentes no alimento.

As amostras submetidas à análise de Reação de Lugol, foram pesadas com massas de $10 \mathrm{~g}( \pm 0,51 \mathrm{~g})$, onde todas as três vias das cinco amostras apresentaram coloração marrom clara, o que caracteriza que o mel não sofreu adulteração por adição de amido e dextrinas. 
$\mathrm{Na}$ análise da reação de Lund as massas pesadas foram de aproximadamente $2 \mathrm{~g}( \pm 0,39 \mathrm{~g})$ onde todas as amostras apresentaram precipitado superior aos $0,6 \mathrm{~mL}$ requerido para caracterizar o mel testado como natural e não artificial. Os dados de massas pesadas e volumes de precipitados obtidos nesta análise estão apresentados na Tabela 1.

Tabela 1 - Resultados da análise de Reação de Lund das cinco amostras de méis

\begin{tabular}{c|c|c}
\hline Amostra & Massa pesada (g) & Volume de precipitado (ml) \\
\hline $\mathbf{A 0 1}$ & 2,01 & 4 \\
\hline $\mathbf{A 0 2}$ & 2,32 & 3 \\
\hline $\mathbf{A 0 3}$ & 3,20 & 5 \\
\hline B01 & 2,42 & 4 \\
\hline B02 & 2,20 & 4 \\
\hline B03 & 3,16 & 5 \\
\hline C01 & 2,06 & 4 \\
\hline 002 & 2,06 & 4 \\
\hline 003 & 2,31 & 4 \\
\hline D01 & 2,00 & 4 \\
\hline D02 & 2,80 & 6 \\
\hline D03 & 2,33 & 5 \\
\hline E01 & 2,56 & 4,5 \\
\hline E02 & 2,39 & 4 \\
\hline E03 & 2,04 & 5 \\
\hline
\end{tabular}

Fonte: Dos Autores (2018).

De acordo com as normas do Instituto Adolfo Lutz (1985), méis que possuem precipitado com valores inferiores à $0,6 \mathrm{~mL}$ são caracterizados como de má qualidade, já que o precipitado é composto de substâncias albuminóides. A ausência deste, implica na perda de proteína durante o processamento do alimento.

Para a análise e adulteração por adição de corantes foram pesadas as cinco amostras em triplicata com massa de $1 \mathrm{~g}( \pm 0,18 \mathrm{~g})$, onde todas as vias das amostras permaneceram com a cor de mel inalterada, não havendo mudança de cor, indicando que não houve adição de corantes. Os valores de $\mathrm{pH}$ obtidos para as amostras foram todos ácidos e permaneceram na faixa de $\mathrm{pH}=3$, os resultados obtidos estão expostos no Figura 2. 
Figura 2 - Valores de $\mathrm{pH}$ das cinco amostras de méis analisados

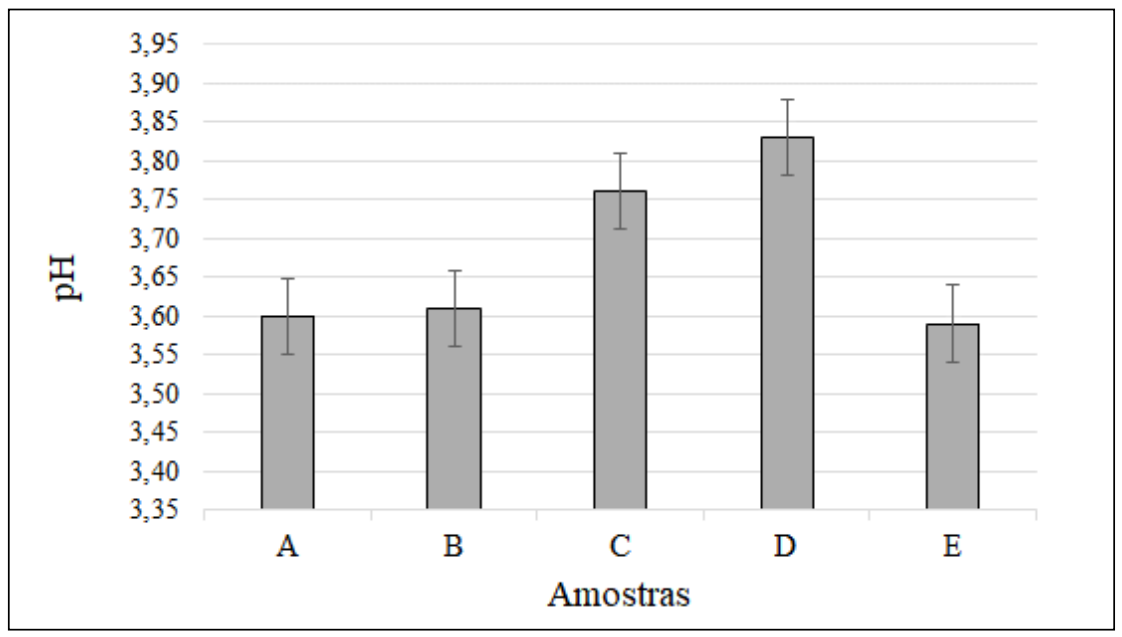

Fonte: Dos Autores (2018).

De acordo com a legislação vigente, os valores de $\mathrm{pH}$ devem permanecer na faixa de 3,3 a 4,6 para serem aptos ao consumo, já que valores de $\mathrm{pH}$ muito baixos interferem de forma significativa nas características sensoriais do produto, assim como valores elevados, podem provocar uma diminuição no controle microbiano existente (BRASIL, 2000).

Os valores de Acidez Livre, Lactônica e Total encontram-se na Tabela 2.

Tabela 2 - Resultados da análise de Acidez das cinco amostras de méis

\begin{tabular}{c|c|c|c|c}
\hline Amostra & $\begin{array}{c}\text { Massa } \\
\text { pesada (g) }\end{array}$ & $\begin{array}{c}\text { Acidez Livre } \\
\text { (meq.kg-1) }\end{array}$ & $\begin{array}{c}\text { Acidez } \\
\text { Lactônica } \\
\text { (meq.kg-1) }\end{array}$ & $\begin{array}{c}\text { Acidez } \\
\text { Total } \\
\text { (meq.kg-1) }\end{array}$ \\
\hline $\mathbf{A 1}$ & 10,20 & 27,54 & 9,62 & 37,16 \\
\hline $\mathbf{A 2}$ & 10,20 & 27,54 & 8,55 & 36,09 \\
\hline B1 & 10,03 & 36,36 & 8,70 & 45,06 \\
\hline B2 & 10,51 & 33,30 & 8,82 & 42,12 \\
\hline C1 & 9,95 & 32,20 & 19,18 & 51,38 \\
\hline C2 & 10,13 & 32,11 & 18,30 & 50,42 \\
\hline D1 & 10,06 & 42,14 & 15,71 & 57,85 \\
\hline D2 & 10,02 & 41,32 & 14,70 & 56,02 \\
\hline E1 & 10,78 & 39,32 & 12,64 & 51,96 \\
\hline E2 & 10,42 & 34,53 & 15,69 & 50,22 \\
\hline
\end{tabular}

Fonte: Dos Autores (2018). 
$\mathrm{Na}$ análise da acidez, constatou-se que apenas o mel A e o mel B enquadraram-se no Regulamento Técnico de Identidade e Qualidade do Mel (BRASIL, 2000), que não deve ultrapassar o valor de 50 miliequivalentes de acidez $/ \mathrm{kg}$ de mel.

A acidez no mel, é resultado de uma variação dos ácidos orgânicos, oriundos do néctar, pela ação de uma enzima chamada glicose-oxidase, que por sua vez, origina o ácido glucônico, através de bactérias durante o processo de maturação do mel, além da quantidade de minerais que está presente no mel (VILHENA, ALMEIDA-MURADIAN, 1999).

De acordo com Evangelista-Rodrigues e colaboradores (2005), há uma diferença significativa para os valores de acidez e umidade em alguns tipos de méis. Isso se dá devido a diversos fatores, dentre eles, o período de maturação do mel, o armazenamento e principalmente, o tipo de abelha que produz o mel. Os valores de acidez elevados para os méis C, D e E podem ser explicados devido a diferentes espécies de abelhas.

Em outro trabalho, Lira e colaboradores (2004) compararam méis de abelhas da espécie Appis Mellifera (abelha africanizada) com méis de abelhas Meliponineas (abelha nativa). Nesse estudo, foi possível observar uma diferença nos valores de acidez para as duas espécies de abelhas muito alta, chegando a obter uma média de $24,14 \mathrm{meq} / \mathrm{kg}$ para as abelhas africanizadas e até $81,01 \mathrm{meq} /$ $\mathrm{kg}$ para as abelhas nativas.

Segundo Silva (2000), há essa diferença provavelmente devido às plantas visitadas pelas espécies de abelhas. De acordo com o autor, já foi verificado, por exemplo, que em vegetações de uso frequente de abelhas africanizadas, as abelhas nativas não foram encontradas. Esse fator pode explicar os valores distintos encontrados nas análises, sugerindo que seja formulada uma nova normativa, para enquadramento das abelhas nativas para os parâmetros de qualidade físico-químicas.

\section{CONCLUSÃO}

Os testes químicos qualitativos realizados neste trabalho não são capazes de identificar todos os tipos de fraude, porém podem auxiliar na detecção das mais comuns que ocorrem no mel, colaborando com o diagnóstico de focos de ações fraudulentas e melhorando a experiência do consumidor de mel no Brasil.

Diante do exposto, as amostras apresentaram um índice de aprovação de $90 \%$, se comparados aos parâmetros recomendados pela legislação brasileira vigente. Os méis testados apresentaram resultado negativo no quesito fraude, assegurando que esses produtos do interior do nordeste gaúcho possuem qualidade em relação aos parâmetros avaliados.

Entretanto, os resultados obtidos para a acidez total para os méis C, D e E ficaram acima do recomendado pela legislação brasileira vigente. A acidez 
no mel é um parâmetro de extrema importância a ser avaliado, já que, além de conferir características químicas e sensoriais, auxilia no controle microbiano.

\section{REFERÊNCIAS}

\section{ABEMEL/MAPA. Câmara Setorial do MEL - MAPA 16/6/2015 APICULTURA} SUSTENTÁVEL. Disponível em: http://www.agricultura.gov.br/assuntos/camarassetoriais-tematicas/documentos/camaras-setoriais/mel-e-produtos-das-abelhas/ anos-anteriores/inteligencia-comercial-abemel-36.pdf. Acesso em: 20 nov. 2018.

ANDRADE, S. E. O. D. et al. Estudo sobre o uso do mel de abelha associado com plantas medicinais na comunidade Várzea Comprida dos Oliveiras, Pombal, Paraíba, Brasil. ACSA, Paraíba, v. 8, n. 3, p. 45-50, set./09. 2012.

AZEVEDO-BENITEZ, A. L. G.; NOGUEIRA-COUTO, R. H. Estudo de algumas dietas artificiais visando a produção de geleia real em colméias de Apis mellifera. In: ENCONTRO SOBRE ABELHAS, 3., 1998, Ribeirão Preto. Anais... Ribeirão Preto: Universidade de São Paulo, Faculdade de Filosofia Ciências e Letras, 1998. p. 227-230.

BENDER, A. E. Dicionário de nutrição e tecnologia de alimentos. São Paulo: ROCA, 1992.

BRASIL. Ministério da Agricultura. Secretaria Nacional de Defesa Agropecuária. Laboratório Nacional de Referência Animal (LANARA). Portaria n 01, de 07 de outubro de 1981. Métodos Analíticos Oficiais para Controle de Produtos de Origem Animal e seus Ingredientes: métodos físicos e químicos. Diário Oficial da União, Brasília - DF, 13 de out de 1981. Disponível em: <http:/ / extranet.agricultura.gov.br/ sislegisconsulta/servlet/VisualizarAnexo?id=13362> Acesso em: 05 nov. 2018.

BRASIL. Ministério da Agricultura, Pecuária e Abastecimento. Instrução Normativa 11, de 20 de outubro de 2000, Regulamento Técnico de identidade e qualidade do mel. Disponível em: <http://www.agricultura.gov.br/sda/dipoa/anexo_intrnorm11. htm> Acesso em: 26 nov. 2018.

EVANGELISTA - RODRIGUES, A.; SILVA, E. M. S. da; BESERRA, M.F.; RODRIGUES, M. L. Análise físico - química de méis das abelhas Apis mellifera e Melípona Scutellaris produzidos em duas regiões no Estado da Paraíba. Ciência Rural, Santa Maria, v. 35, n. 5, p. 1166- 1171, set- out, 2005.

FAO - Food and Agriculture Organization of the United Nations. Beekeeping in Asia. FAO Agricultural Services Bulletin 68/4. Roma. 1990. Disponível em:<http://www. fao.org/docrep/X0083E/X0083E00.htm>. Acesso em: 11 jan. 2019.

FINCO, Fernanda Dias Bartolomeu Abadio; MOURA, Luciana Learte; SILVA, Igor Galvão. Propriedades físicas e químicas do mel de Apis mellifera L. Ciência e Tecnologia de Alimentos, Campinas, v. 30, n. 3, p. 706-712, jul./set. 2010. 
IBGE. Pesquisa da pecuária municipal - ppm. Disponível em: <https:/ / www.ibge. gov.br/estatisticas-novoportal/economicas / agricultura-e-pecuaria/9107-producaoda-pecuaria-municipal.html?=\&t=resultados>. Acesso em: 11 jan. 2019.

INSTITUTO ADOLFO LUTZ. Métodos físico-químicos para a análise de alimentos. São Paulo, 1020 p. 2008.

INSTITUTO ADOLFO LUTZ. Normas Analíticas do Instituto Adolfo Lutz. v. 1:

Métodos químicos e físicos para análise de alimentos, $3^{\text {a }}$ ed. São Paulo: IMESP, 1985. p. 164.

LIRA, A. F. et al. Estudo comparativo do mel de Appis Mellifera com méis de

Meliponineos. Ciência Rural, Santa Maria, v. 34, n. 5, p. 1623-1624, set./out. 2004.

ROSSI, N.F.; MARTINELLI, L.A.; LACERDA, T.H.M.; CAMARGO, P.B.; VICTORIA, R.L. Análise da adulteração de méis por açúcares comerciais utilizando-se a composição isotópica de carbono. Ciência e Tecnologia de Alimentos, Campinas, v.19, n.2, p.199-200, 1999.

SILVA, R.A. Fenologia e forrageamento pelos Apidae em plantas do módulo de apicultura do CCA/UFPB/Campus III -Areia (Microrregião do Brejo Paraibano). 2000. 50f. Monografia (Graduação em Zootecnia) - CCA, Universidade Federal da Paraíba.

VILHENA, F.; ALMEIDA-MURADIAN, L.B. Manual de análises físico-químicas do mel. São Paulo-SP: APACAME, 1999. 16p. 